\title{
REFLECTIVE PRACTICE ON INSTRUCTIONAL PLANNING: RELEVANCE AND CONTRIBUTION TO PRE-SERVICE TEACHERS' PROFESSIONAL DEVELOPMENT
}

\author{
Wan Nurul Elia Haslee Sharil ${ }^{1}$, Chris Kyriacou ${ }^{2}$ \\ ${ }^{1}$ Ms., Universiti Teknologi MARA, Malaysia, eliasharil@yahoo.com \\ 2 Prof. Dr., University of York, United Kingdom, chris.kyriacou@york.ac.uk
}

\begin{abstract}
Over the years, a number of researches have investigated reflective practice. The areas of reflective practice researched include investigating teacher belief and intention, knowledge formation and teacher actions. A distinction between in-service and pre-service teachers has also been made in recognition of the different dynamics that these two groups of teachers possess. This paper explores the impact that reflective practice can have in developing pre-service teachers' professional development, particularly on instructional planning, by focusing on what entails reflective practice and instructional planning, the dimensions that underpin reflection, and how the convergence between reflection and instructional planning may contribute to preservice teachers' professional development.
\end{abstract}

Keywords: Reflective practice, pre-service teachers, teacher education, teacher training

\section{INTRODUCTION}

Reflective practice, particularly among pre-service teachers, has been widely researched over the years. Tillema (2000) points out that reflection-oriented learning is essential to ensure professional growth among student teachers, while Lee (2005) and Pultorak (2014) claimed that reflection is a must if a teacher has any intention to suit their teaching to their students' needs. Both statements indicate the significant position of reflective practice in pre-service teachers' professional development.

One of the aims of training pre-service teachers includes the ability of the pre-service teachers to come up with sound instructional plans (Baylor, Kitsantas \& Hu, 2003). Pre-service teachers typically undergo methodology or curriculum study courses that would guide them on drafting good instructional plans. The process of becoming an effective instructional planners depends on a number of factors such as the preservice teachers self-efficacy, cognitive and metacognitive strategies, pre-service teachers' beliefs as well as their ability to adapt their theoretical knowledge towards practice (Baylor \& Kitsantas, 2005), which indicates the intricate process of instructional planning.

Therefore, this paper aims to put forth suggestions on how reflections on instructional planning can be encouraged among pre-service teachers. The paper is divided into several sections; a review on research that has been carried out on reflective practice and instructional planning, the significance of reflecting on instructional planning and efforts that can be taken to encourage reflection on instructional planning among pre-service teachers. 


\section{REFLECTIVE PRACTICE AND INSTRUCTIONAL PLANNING: AN OVERVIEW}

\subsection{Reflective Practice}

In training the teachers of tomorrow, the term reflective practice is not novel to teacher trainers and teacher training institutions. But what constitutes reflective practice?

Reflective practice is ambiguous in the sense that there is no fixed and concrete, agreed upon definition to as what it entails (Yesilbursa, 2011). However, the review of literature has provided some insight into how proponents of reflective practice define and decide what establishes the notion. Scholars have provided various definitions that vary from more philosophical aspects of epistemological development among teachers to more practical conceptions of reflective practice.

Dewey (1933) was among the earliest scholars whom coined the term 'reflective thinking'. He perceives the term reflective practice by putting forward philosophical advances on what constitutes thinking in his book How We Think. In this book, he suggested that reflective thoughts are not only those that happen in sequence, but in consequence; a consecutive order of ideas that determines the outcome. Dewey (1933) also suggested that these outcomes largely depend on the preceding events or ideas. This strongly provided grounds to suggest that reflection involves a recursive cycle, and not a linear one. Lee (2005) reiterated this process by suggesting that reflection is not simply a process towards finding an absolute solution, but raising the practitioners' awareness in doing so. Fifty years after Dewey (1933) proposed the term reflective thoughts, Schon (1983) extended Dewey's (1933) proposition on reflection by exploring in detail what entails reflective practice among professionals, including teachers. He further focused on developing the notion reflection-on-action and reflection-in-action, which gained popularity among academic researchers.

On a more practical stand, Loughran (2002) defined reflective practice as "a well-defined and crafted practice that carries very specific meaning and associated action" (p. 33). He further added that being able to reflect on one's own teaching requires the teacher to make meaning from the teaching situation so that he could better understand the art of teaching practice. Richards (1996) further corroborated by mentioning the steps needed to be taken by teachers in which they would collect data about teaching, examine their attitudes, beliefs, assumptions and teaching practices and these are utilized for critical reflection to occur. Richards (1996) and Loughran's (2002) echoed Schon's (1987) thoughts, which think reflection is central to a teachers' professional growth. These definitions resonate the position of reflective practice in a teacher-training course. Reflective practice is a complicated concept, which requires scaffold from experts, if it were to be implemented in a teacher-training course. It is more than just thinking about what to do in teaching and learning; it requires the teacher to take a step back and re-examine their decisions, be it their pedagogy or classroom management, to be implemented in their next lesson.

When scholars discuss or propose models that constitute reflective practice, two dimensions that are relevant to the present study was identified from the literature review; which constitutes the temporal and the complexity dimensions; or commonly identified as types of reflection that occur at different stages of teaching as well as the levels of reflection that teachers engage in. The dimensions discussed in this section are not in any way exhaustive of the types of reflective models that has been proposed over the years.

The first dimension of reflection is examined from a temporally distributed perspective (Conway, 2001). Temporality in the field of reflective practice is used to indicate the space of time. Proponents of reflective practice from the temporally distributed perspective examined and proposed different types of reflection that occur at different points of teaching stages; namely before teaching begins, during the teaching action and after teaching has ended. Van Manen (1991) attributed the reflection that occur during these sequential events as anticipatory reflection, contemporaneous reflection and retrospective reflection. Conway (2001) described anticipatory reflection as "future-oriented reflection before action" (p. 90). Retrospective reflection, or recollective reflection (Etscheidt et al., 2012) is in contrast of anticipatory reflection; where it deals with "pastoriented reflection after action (Conway, 2001, p. 90). While anticipatory reflection deals with reflection on future plans, the retrospective reflection takes on to look back at teaching events that have ended, in order to gain perspective into teaching (Etscheidt et al., 2012).

Akbari (2007) elaborated Schon's (1983) concept of reflection-on-action as the type of reflection that occur after an event has ended; which indicated the similarity to Van Manen's (1991) idea of retrospective reflection. In between future-oriented reflection and past-oriented reflection, Van Manen (1991) in Etscheidt et al. (2012) also identified active or interactive reflection, which allows practitioners to think and support on-the-spot decisions; which is a typical phenomenon in teaching. Schon (1983) attributed this kind of reflection as reflection-in-action. Akbari (2007) and Ball, Knobloch and Hoop (2007) noted that this kind of reflection as 
"online reflection" that practitioners or teachers will encounter during their teaching actions; which may be difficult to be executed by some practitioners due to the demanding nature of thinking-on-your-feet. In Farrell (2014), reflection-in-action is described as a more immediate type of reflection; where teachers will have to make decisions on spontaneous, in-class incidents, for example, on students' response to the activity. To sum up, the temporal dimension of reflective practice examines reflection that happens at different points in time of the events happening; mainly before, while and after.

The second dimension that is relevant to the present paper addresses reflection in terms of stages or levels of reflective processes. There are different thoughts on how stages or levels of reflective processes are defined. Akbari (2007) in review of Jay and Johnson's (2002) work on the steps that one needs to take in being reflective indicated that the higher level a practitioner goes, a more comprehensive understanding will be gained and the highest level will be the determining factor of change that takes place in teaching. On the other hand, Lee (2005) differed in this by stating that the progress in the stages of reflective practice do not indicate the solution, as he argued that any stages of reflection that takes place can be done reflectively, or unreflectively. Lee (2005) then moved on to stress on the importance on looking at the progress and process as a unit, which should not be viewed as different entities. These differences in view are perhaps contributed by the nature of work presented by the different scholars. Some consider the higher level of reflection you are engaged in, the more differences you can make (Jay \& Johnson, 2002); while for some, the stages of reflection can be examined as domains that can overlap one another (Zeichner \& Liston, 2013).

Van Manen (1977) was among the earliest scholars to propose levels of reflection. He identified three main levels, which are technical rationality, deliberative rationality and critical rationality. Van Manen (1977) described technical rationality as focusing on the process to achieve an end, to which the end is not the priority at this level. This includes the practitioner to be efficient and effective in applying their educational knowledge to achieve the end (Zeichner \& Liston, 1987). Deliberative rationality is the second level of reflection proposed by Van Manen (1977). This level deals with the analysis of underlying assumptions that shapes practice (Zeichner \& Liston, 1987) and looking at placing theory into practice (Lee, 2005). The most complex level of reflection proposed by Van Manen (1977) is critical rationality; which deals with the moral and ethical aspects of practice (Zeichner \& Liston, 1987). Zeichner and Liston (1987) proposed an interesting observation on the levels of reflections proposed by Van Manen (1977). The distinguishing factor between the levels of reflection lies in the degree of comprehension on what is considered as problematic in practice (Zeichner and Liston, 1987).

In training future teachers, it is important to acknowledge that reflection plays a very important role in enhancing their professional development. Teacher trainers ought to also put in a conscious effort to help the pre-service teachers to move within the levels of reflection. The ultimate aim of having reflective pre-service teachers is not to aim that they achieve the highest level of reflection, but to allow them to move within the levels, as this encourages flexibility in their thoughts when they are engaged with their teaching practice.

\subsection{Instructional Planning}

The term pre-service teachers, trainee teachers and student teachers are often used to describe groups of students studying to become teachers. They may include those who do it at schools of education in universities or those trained in teacher training colleges. In training these future teachers, one aspect that has always been emphasized on is training them to write effective instructional plans. Ball et al. (2007) proposed that the processes of instructional planning may be examined in two ways; which is on either "a set of psychological processes in which a person visualizes the future, inventories means and ends, and constructs a framework to guide his or her action" (p. 57) or as Clark and Peterson (1986) in Ball et al. (2007) put forth "the things that teachers do when they say that they are planning" (p.260). Given the powerful position of instructional planning has in teaching, this section provide insight into the approaches to instructional planning, determining factors of successful instructional planners, as well as the educational benefits that effective instructional plans have.

In approaches to instructional planning, Farrell (2014) developed the notion of forward planning, central planning and backward planning. He proposed that forward planners identify the content of a lesson prior to deciding on the methodology that is going to be used in a particular lesson. On the contrary, in central planning, Farrell (2014) indicated that teachers select the methods to be used in teaching first before selecting the content to be delivered to the students. Backward planning begins with the decisions made on the lesson outcomes before deciding on the instructional activities. Farrell (2014) reiterated that these different approaches determine the direction of the lesson in terms of the lesson development, material selection as well as the role of the teachers and the students. Besides the approaches suggested by Farrell (2014), Baylor and Kitsantas (2005) emphasized on the instructivist and constructivist approaches to instructional planning. 
The instructivist approach to planning highlighted the importance of input from the teachers; essentially placing the lesson on the teacher-centered approach (Baylor \& Kitsantas, 2005). On the other hand, Baylor and Kitsantas (2005) suggested learner-centered instruction as the driving core of the constructivist approach to planning. These two different approaches has evolved over the years, in which learner-centered instruction gained much more popularity than teacher-centered approaches.

Although a significant number of hours are spent on training pre-service teachers to do so, the success of doing this depends on many factors. Baylor et al. (2002) suggested that designing a lesson requires more than just knowing what elements are needed in the instructional plan. Among the success determining factor identified by Baylor and Kitsantas (2005) includes the pre-service teachers' beliefs about instructional planning, available cognitive and metacognitive strategies and ability to integrate theoretical approaches to planning the instruction. Baylor and Kitsantas (2005) further explained that self-efficacy plays a very important role in influencing the pre-service teachers to engage themselves in the task. This requires the pre-service teachers to believe that they can bring change to the task at hand. Due to the poorly structured nature of instructional planning, the pre-service teachers are also required to possess some level of metacognitive strategies to organize, to self-monitor, and to have the ability to think flexibly (Baylor and Kitsantas, 2005). Finally, Baylor and Kitsantas (2005) also suggested that in order to become effective instructional planners, pre-service teachers must be able to employ various strategies to suit different instructional approaches.

There are many educational benefits that effective instructional plans have. An effective instructional plan is an indication of teacher expertise (Farrell, 2013) and teacher competence (Ruys et al., 2012). Farrell (2013) in his study found that one aspect that expert teachers perform is the ability to design informed instructional plans. In addition, Ruys et al. (2012) summarized the work of several authors on the significance of instructional plan analysis with regards to teacher competence. In other words, to summarize Ruys et al (2012), if one were to evaluate the level of expertise or competency of a teacher, a good indicator will be on their instructional plan design. However, the most interesting work cited by Ruys et al. (2012) was of Naafs et al. (2002) and Meyen and Greer (2009); which suggested that there is relationship between instructional planning and teaching quality in the aspect of student achievement and teaching behavior. Although planning and execution are two entirely different processes, preparing pre-service teachers to design effective instructional plans will ensure that they have a good start to a successful lesson. In addition to teaching quality, Hooder and Hollongsworth (1975) in Ball et al. (2007) proposed that an effective instructional plan also provides educational benefits; such as serving as a guideline for teachers, providing the teacher some time space to motivate his or her students, as well as allowing the teacher to evaluate what they have achieved in class and to improve their teaching. This will allow teachers to have empirical evidence as their source of reference, when they are certain of their teaching that they would like to improve on. For example, when an activity does not go well, a teacher may turn to their instructional plan, and check what activities were done, and in what manner was it done in. In other words, it allows the teacher to travel back to a lesson that has ended, by examining his or her lesson plan.

This section has addressed the different approaches to instructional planning the factors that determines effective instructional plan designs, benefits that effective instructional plans have towards teaching and learning. The next section will address another pertinent issue in this research; which is the significance of reflection on instructional planning.

\section{REFLECTIONS ON INSTRUCTIONAL PLANNING: WHY AND HOW}

\subsection{The Significance}

Due to the benefits that reflective practice brings to the education field, it is becoming a dominant paradigm in the international teacher education scene (Odeh, Kurt and Atamturk, 2012). Odeh et al (2012) further elaborated on how reflective practice can help shape the professionalism and professional growth of teachers, which results in teachers becoming more alert with their practices. Although Odeh et al (2012) in their study has found that training does not seem to have an impact in terms of learning new things in the classroom while teaching, Hinett and Weeden (2000) proposed that pre-service teachers perceived that the critical and challenging comments that they received as a result of a reflection positively influenced them to become better teachers, implying that there is a need for training reflective practice among pre-service teachers. The previous section which reviewed the different temporal dimensions of reflective practice has indicated that reflection may also occur before an action is taken before teaching happens. This brings us to the discussion of next section -why and how can reflection be encouraged during instructional planning. 
In coming up with effective instructional plans, Baylor and Kitsantas (2005) indicated the need to tap into the pre-service teachers' available cognitive and metacognitive strategies and ability to integrate theoretical approaches to planning the instruction. Dewey (1933), on the other hand, described reflective practitioners as active, persistent, and carefully consider any form of knowledge and the consequences of that knowledge. He further added on by saying that a reflective practitioner will have hesitations in their thinking and will continuously search for an answer that could diminish their doubt in constructing knowledge. Being experimental and knowledgeable will then lead the practitioner towards better understanding of what they know and do by reconsidering all their actions (Loughran, 2002). This indicates that reflective practice goes beyond than just thinking. It requires the person to thoughtfully experiment different solutions in trying to overcome any problems that he or she encounters in his or her profession (Schon, 1993). This clearly indicates that reflective practice will lead to better understanding of one's own practice, when it is crafted well against many different structures of thinking, and in this case, during instructional planning. It is at this juncture that we could analyze the significance of reflections on the instructional planning process.

In the temporal dimension of reflective practice, there is a notion of anticipatory reflection. Anticipatory reflections are considered as thoughts that are concerned with the teachers' instructional plans before she begins her lessons; or more specifically, the thoughts that occur during the design process of a lesson plan. Farrell (2014) indicated a similar type of reflection in his Framework for Reflecting on Practice, coined as reflection-for-action. Farrell (2014) made a similar point when he indicated that this type of reflection requires the teachers to anticipate what will occur during the lesson, as well as reflect on their past experiences before a lesson occurs. This type of reflection fits well with Ball et al. (2007) description of the first step of teachers thought processes, which is thinking before the actual teaching takes place. This also signifies the importance of reflections on instructional planning.

\subsection{Efforts to Encourage Reflection on Instructional Planning}

The literature has presented that reflection and reflective practice can be manifested in many ways such as in portfolios, journals, and even videos (McMullan, 2006; Pavlovich, 2007 and Powell, 2005). The different ways in manifesting reflection depends largely on the institutional decisions. Xu (2009) elaborated on several procedures for reflective teaching namely peer observation, written accounts of experiences, self-reports, teacher diaries, recording lessons, reflective inquiry groups and collaborative action research. However, the important question to be addressed in this section is how can we help the pre-service teachers to reflect better during the instructional planning process? In this section, two tools will be briefly described and it is hoped that by providing an overview of these tools, more concerted effort can be taken in aiding pre-service teachers to reflect during instructional planning.

Instructional Planning Self-Reflective Tool (IPSRT) and Constructivist Planning Self-Reflective Tool (CPSRT) are tools developed by Baylor, Kitsantas and Chung in 2001 in effort to help the pre-service teachers to fulfill the students' needs by reflecting on their instructional planning. Both tools were based on the instructivist and the constructivist approach in instructional planning. Both tools were designed to be used after the instructional plan has been drafted. The tool can then be referred to, as it provides a checklist of items that needs consideration from the pre-service teachers. Both tools provided checklist for generic aspects that are typically found in an instructional plan. Due to the different natures of both instructivist and constructivist approach to lesson planning, the aspects that are included in both tools differ in this sense. The effort taken by Baylor et al (2001) has given an option for the pre-service teachers to turn to in helping them to reflect during instructional planning.

Ho (1995) came up with a suggestion to use lesson plans in aiding reflection among pre-service teachers. As compared with Baylor et al (2001), Ho's (1995) work differ because she suggested using the lesson plan in a recursive manner in order to improve on it. What she did was to reflect on what had transpired during a lesson, and using that reflection to go back to the same lesson plan, and make necessary changes accordingly. This in turn will help the pre-service teachers to carry out a better-informed decision making process for the subsequent lessons. This process is well aligned with Dewey's (1933) concept of reflection happening as a consequence of preceding events. The rationale behind making changes to the same lesson plan ensures that the pre-service teachers are more involved in a process of growth and self-development (Ho, 1995).

\section{CONCLUSION}

This paper has recapitulated some important concepts in reflective practice among pre-service teachers; focusing on instructional planning in particular. The conceptual review of past research has indicated the potential that reflective practice on instructional planning, and how this might aid the pre-service teachers to 
improve on their practice. In conclusion, focusing on instructional planning might escalate a pre-service teachers' experience and development, if they receive rigorous feedback and are carefully guided through the experience.

\section{REFERENCE LIST}

Akbari, R. (2007). "Reflections on Reflection: A Critical Appraisal of Reflective Practices in L2 Teacher Education". System. 35(2), 192-207.

Ball, A. L., Knobloch, N. A., \& Hoop, S. (2007). "The Instructional Planning Experiences of Beginning Teachers". Journal of Agricultural Education. 48(2), 56-65.

Bandura, A. (2012). On the functional properties of perceived self-efficacy revisited. Journal of Management, 38(1), 9-44.

Baylor, A., Kitsantas, A. \& Chung, H. (2001). The Instructional Planning Self Reflective Tool: A Method for Promoting Effective Lesson Planning. Educational Technology. 41(2). 56-59.

Baylor, A. L., Kitsantas, A. (2005). A Comparative Analysis and Validation of Instructivist and Constructivist Self-Reflective Tools (IPSRT and CPSRT) for Novice Instructional Planners. Journal of Technology and Teacher Education, 13(3), 433-457.

Chitpin, S., Simon, M., \& Galipeau, J. (2008). Pre-service teachers' use of the objective knowledge framework for reflection during practicum. Teaching and Teacher Education, 24(8), 2049-2058.

Colton, A. B., \& Sparks-Langer, G. M. (1993). A conceptual framework to guide the development of teacher reflection and decision making. Journal of Teacher Education, 44(1), 45-54.

Conway, P. F. (2001). Anticipatory reflection while learning to teach: From a temporally truncated to a temporally distributed model of reflection in teacher education. Teaching and Teacher Education, 17(1), 89-106.

Dewey, J. (1933). How we think: Courier Corporation: New York.

Etscheidt, S., Curran, C. M., \& Sawyer, C. M. (2011). Promoting reflection in teacher preparation programs: A multilevel model. Teacher Education and Special Education: The Journal of the Teacher Education Division of the Council for Exceptional Children, 0888406411420887.

Farrell, T. S. (2013). Reflecting on ESL teacher expertise: A case study. System, 41(4), 1070-1082.

Hinett, K., \& Weeden, P. (2000). How Am I Doing?: developing critical self-evaluation in trainee teachers. Quality in Higher Education, 6(3), 245-257.

Ho, B. (1995). Using Lesson Plans as a Means of Reflection. ELT Journal. 49(11). 66- 71.

Jay, J. K., \& Johnson, K. L. (2002). Capturing complexity: a typology of reflective practice for teacher education. Teaching and Teacher Education, 18(1), 73-85.

Lee, H.-J. (2005). Understanding and assessing preservice teachers' reflective thinking. Teaching and Teacher Education, 21(6), 699-715.

Loughran, J. J. (2002). Effective reflective practice in search of meaning in learning about teaching. Journal of Teacher Education, 53(1), 33-43.

Popper, K. (1959). The logic of scientific discovery. New York: Basic Books.

Pultorak, E. G. (2014). Reflectivity and Cultivating Student Learning: Critical Elements for Enhancing a Global Community of Learners and Educators: Rowman \& Littlefield.

Ruys, I., Van Keer, H., \& Aelterman, A. (2012). Examining Pre-Service Teacher Competence in Lesson Planning Pertaining to Collaborative Learning. Journal of Curriculum Studies, 44(3), 349-379.

Schön, D. A. (1983). The reflective practitioner: How professionals think in action (Vol. 5126): Basic books. College Record, 104(7), 1393-1421.

Tillema, H. H. (2000). Belief change towards self-directed learning in student teachers: immersion in practice or reflection on action. Teaching and Teacher Education, 16(5-6), 575-591. 
Pavlovich, K. (2007). The development of reflective practice through student journals. Higher Education Research \& Development, 26(3), 281-295.

Poom-Valickis, K. (2014). Novice Teachers' Professional Development During the Induction Year. ProcediaSocial and Behavioral Sciences, 112, 764-774.

Powell, E. (2005). Conceptualising and facilitating active learning: teachers' video-stimulated reflective dialogues. Reflective Practice, 6(3), 407-418.

Van Manen, M. (1995). On the epistemology of reflective practice. Teachers and Teaching: Theory and Practice, 1(1), 33-50.

Qing, X. (2009). Reflective Teaching--an Effective Path for EFL Teacher's Professional Development. Canadian Social Science, 5(2), 35-40.

Yesilbursa, A. (2011). Reflection at the interface of theory and practice: an analysis of pre-service English language teachers' written reflections. Australian Journal of Teacher Education, 36(3), 6.

Zeichner, K. M., \& Liston, D. P. (2013). Reflective Teaching: An Introduction: An Introduction: Routledge.

Zwozdiak-Myers, P. (2010). Teacher as a researcher/reflective practitioner. Learning to teach physical education in the secondary school: A companion to school experience, 1265. 